\title{
SOSIALISASI PELATIHAN UNTUK MENINGKATKAN PRESTASI KERJA KARYAWAN DI PDAM TIRTANADI CABANG PADANG BULAN MEDAN
}

\author{
Reza Nurul Ichsan ${ }^{1)}$, Lukman Nasution ${ }^{2)}$ \\ Universitas Pembinaan Masyarakat Indonesia ${ }^{1)}$ \\ Universitas Muslim Nusantara Al Washliyah ${ }^{2}$ \\ rezaichsan31@gmail.com \\ lukmanumnaw@gmail.com
}

\begin{abstract}
ABSTRAK
Pelatihan yang baik akan menghasilkan prestasi kerja yang baik pula sehingga menguntungkan perusahaan maupun karyawan, sebaliknya pelatihan yang buruk akan memberikan dampak merugikan bagi karyawan maupun perusahaan sehingga tujuan dari pada perusahaan tidak tercapai. Pelatihan terhadap sumber daya manusia menjadi kebutuhan yang akan menunjang perusahaan untuk meningkatkan kemampuan, yakni kemampuan perusahaan untuk tetap bertahan dan bersaing di era globalisasi ini. Pengabdian ini dilaksanakan di PDAM Tirtanadi Cabang Padang Bulan Medan. metode pelaksanaan yang digunakan adalah melalui kegiatan ceramah, diskusi dan tanya jawab tentang pelatihan untuk meningkatkan prestasi kerja karyawan di PDAM Tirtanadi Cabang Padang Bulan Medan. Acara sosialisasi ini melibatkan seluruh pegawai di lingkungan PDAM Tirtanadi Cabang Padang Bulan Medan untuk lebih memahamkan pentingnya pelatihan untuk meningkatkan prestasi kerja karyawan di PDAM Tirtanadi Cabang Padang Bulan Medan. Adapun hasil diskusi dalam kegiatan Sosialisasi pelatihan untuk meningkatkan prestasi kerja karyawan di PDAM Tirtanadi Cabang Padang Bulan Medan dapat berjalan dengan lancar. Semua peserta terlihat antusias dan merasakan manfaatnya. Keberhasilan ini ditunjukkan antara lain: (1) adanya kesesuaian materi dengan kebutuhan para guru untuk memahami tentang keselamatan kerja di lingkungan PT. PLN (Persero) Unit Induk Pembangunan II Medan. (2) adanya respon yang positif dari peserta yang ditunjukkan dengan adanya diskusi yang cukup hangat dalam rangka implementasi keselamatan kerja di lingkungan PT. PLN (Persero) Unit Induk Pembangunan II Medan.
\end{abstract}

Kata Kunci : Pelatihan Kerja, Prestasi Kerja Karyawan

\begin{abstract}
Good training will also produce good work performance so that it benefits the company and employees, on the other hand, bad training will have a detrimental impact on both employees and the company so that the goals of the company are not achieved. Training for human resources is a necessity that will support companies to improve their capabilities, namely the company's ability to survive and compete in this era of globalization. This service was carried out at PDAM Tirtanadi Padang Bulan Branch, Medan. The implementation method used is through lectures, discussions, and questions and answers about training to improve employee work performance at PDAM Tirtanadi, Padang Bulan Branch, Medan. This socialization event involved all employees in the PDAM Tirtanadi Padang Bulan Medan branch to better understand the importance of training to improve employee work performance at PDAM Tirtanadi, Padang Bulan Branch, Medan. The results of the discussion in the training socialization activities to improve employee work performance at PDAM Tirtanadi Padang Bulan Medan branch went well. All participants looked enthusiastic and felt the benefits. This success is shown, among others: (1) the suitability of the material with the needs of teachers to understand work safety in the PT. PLN (Persero) Parent Development Unit II Medan. (2) there is a positive response from the participants which is indicated by the existence of a fairly warm discussion in the context of implementing work safety in the PT. PLN (Persero) Parent Development Unit II Medan.
\end{abstract}

Keywords: Job Training, Employee Performance 


\section{PENDAHULUAN}

Pelatihan yang baik akan menghasilkan prestasi kerja yang baik pula sehingga menguntungkan perusahaan maupun karyawan, sebaliknya pelatihan yang buruk akan memberikan dampak merugikan bagi karyawan maupun perusahaan sehingga tujuan dari pada perusahaan tidak tercapai. Pelatihan terhadap sumber daya manusia menjadi kebutuhan yang akan menunjang perusahaan untuk meningkatkan kemampuan, yakni kemampuan perusahaan untuk tetap bertahan dan bersaing di era globalisasi ini.

Pelatihan memberikan pengaruh terhadap kemampuan para karyawan yang akan dikembangkan serta dapat memberikan semangat serta membina karyawan agar mampu untuk bekerja mandiri dan juga dapat menumbuhkan kepercayaan diri karyawan sehingga prestasi kerjanya semakin meningkat.

Peningkatan prestasi kerja karyawan dalam perusahaan didukung oleh pelatihan yang memiliki peran yang cukup vital dalam pengelolaan sumber daya manusia diperusahaan terutama menyangkut produktivitas karyawan, sebab prestasi kerja merupakan hasil dari perilaku kerja dapat dimotivasi melalui sistem pelatihan dan pemberian insentif yang adil bagi karyawan.

Dari hasil pengamatan, dapat diidentifikasi beberapa persoalan berikut:

1. Pada PDAM Tirtanadi Cabang Padang Bulan Medan sebenarnya sudah menerapkan pelatihan kerja. Namun, karena para karyawan kadang sepele dengan pelatihan kerja sehingga mengakibatkan sering melakukan kesalahan dalam bekerja.

2. Masih kurangnya pengetahuan para karyawan bahwa pentingnya pelatihan sebelum kerja

Adapun tujuan dari kegiatan pengabdian masyarakat ini adalah :

1. Menambah wawasan dan pemahaman tentang pelatihan kerja di PDAM
Tirtanadi Cabang Padang Bulan Medan

2. Berbagi pengetahuan dalam implementasi tentang pelatihan kerja.

Hasil kegiatan yang dapat dirasakan atau diterima oleh pegawai PDAM Tirtanadi Cabang Padang Bulan Medan, setelah mengikuti penyuluhan diharapkan para pegawai di lingkungan PDAM Tirtanadi Cabang Padang Bulan Medan:

1. Memahami materi tentang pelatihan kerja untuk meningkatkan prestasi kerja pegawai di lingkungan PDAM Tirtanadi Cabang Padang Bulan Medan

2. Mampu mengimplementasikan pelatihan yang didapat di dalam dunia kerja di lingkungan PDAM Tirtanadi Cabang Padang Bulan Medan.

\section{METODE PELAKSANAAN}

Kegiatan ini akan dilakukan di PDAM Tirtanadi Cabang Padang Bulan Medan. Dalam kegiatan ini akan melibatkan seluruh pegawai di lingkungan PDAM Tirtanadi Cabang Padang Bulan Medan. Dalam kegiatan ini diharapkan peserta mempunyai kemauan untuk mengikuti sosialisasi pelatihan kerja dalam meningkatkan prestasi kerja pegawai di lingkungan PDAM Tirtanadi Cabang Padang Bulan Medan.

Kegiatan ini akan dilaksanakan dengan metode sosialiasi yang dilaksanakan dengan cara ceramah, tanya jawab dan konseling tentang pelatihan kerja di lingkungan PDAM Tirtanadi Cabang Padang Bulan Medan. Secara lebih rinci metode kegiatan ini adalah sebagai berikut :

a) Ceramah singkat, digunakan untuk menyampaikan sejumlah informasi, dibantu dengan modul dan media belajar keterampilan.

b) Tanya jawab, digunakan selama proses penyuluhan dan konseling.

c) Sosialisasi dan konseling, digunakan untuk memperlihatkan langkah kerja setiap materi yang diberikan. 
d) Melakukan sosialisasi yang dipusatkan di PDAM Tirtanadi Cabang Padang Bulan Medan.

\section{HASIL DAN PEMBAHASAN}

Peserta penyuluhan terlihat antusias dengan materi penyuluhan yang diberikan. Hal ini terlihat dari antusiasnya para peserta dengan diskusi yang aktif dari awal acara sampai dengan berakhirnya acara.

Secara umum, penyuluhan ini berjalan dengan lancar. Hal ini karena dukungan sepenuhnya oleh pihak sekolah, tempat berlangsungnya penyuluhan yang berupa sarana dan prasarana penyuluhan serta bantuan dalam mengumpulkan peserta penyuluhan.

Setiap perusahaan harus menerima kenyataan, bahwa eksistensinya pada masa depan tergantung pada Sumber Daya Manusia (SDM). Dibawah ini beberapa defenisi pelatihan menurut para ahli antaranya adalah:

Rivai (2009 :211) mengungkapkan bahwa "pelatihan merupakan wahana untuk membangun SDM menuju era globalisasi yang penuh dengan tantangan". Sedangkan menurut Kasmir (2016:126) mengatakan bahwa "pelatihan merupakan proses untuk membentuk dan membekali karyawan dengan menambah keahlian, kemampuan, pengetahuan,dan perilakunya". Dapat disimpulkan bahwa pelatihan pada dasarnya merupakan sebuah proses untuk meningkatkan kompetensi karyawan. Pelatihan merupakan sarana ampuh mengatasi bisnis masa depan yang penuh dengan tantangan dan mengalami perubahan yang sedemikian cepat.

\section{- Tujuan Pelatihan}

Adapun Tujuan dari pada pelatihan diantaranya adalah sebagai berikut:

a. Untuk meningkatkan keterampilan karyawan sesuai dengan perubahan teknologi

b. Untuk mengurangi waktu belajar bagi karyawan baru agar menjadi kompeten. c. Untuk membantu masalah operasional.

d. Untuk menyiapkan karyawan dalam promosi.

- Manfaat Pelatihan

a. Manfaat Untuk Karyawan

1. Membantu mendorong dan mencapai pengembangan diri dan rasa percaya diri.

2. Membantu karyawan mengatasi stress, tekanan, frustasi, dan konflik.

3. Meningkatkan kepuasan kerja dan pengakuan.

4. Memenuhi kebutuhan personal peserta dan pelatih.

b. Manfaat Untuk Perusahaan

1. Memperbaiki moral SDM.

2. Membantu karyawan untuk memenuhi ujuan perusahaan.

3. Membantu menciptakan image perusahaan yang lebih baik.

c. Manfaat dalam Hubungan SDM, intra dan antar group dan pelaksanaan kebijakan

1. Meningkatkan komunikasi antar group dan individual.

2. Membantu dalam orientasi bagi karyawan baru dan karyawan transfer atau promosi.

3. Memberikan informasi tentang hokum pemerintah dan kebijakan internasional.

- Jenis - jenis Pelatihan

Menurut Siagian (2008:78) jenis jenis pelatihan kerja adalah sebagai berikut:

1. Pelatihan Kahlian

2. Pelatihan Ulang

3. Pelatihan Lintas Fungsional

4. Pelatihan Tim

5. Pelatihan Kreativitas

- Faktor - faktor yang mempengaruhi Pelatihan Kerja

Ada beberapa faktor - faktor yang 
mempengaruhi pelatihan kerja yaitu :

1. Dukungan manajemen puncak

2. Komitmen para spesialis dan generalis

3. Kompleksitas organisasi

4. Gaya belajar

5. Fungsi - fungsi Sumber Daya Manusia lainnya

\section{- Sasaran Pelatihan}

Sasaran pelatihan dan pengembangan SDM adalah sebagai berikut:

1. Meningkatkan Produktivitas kerja

2. Meningkatkan mutu kerja

3. Meningkatkan ketepatan dalam perencanaan SDM

4. Meningkatkan moral kerja

5. Menjaga kesehatan dan keselamatan

6. Menunjang pertumbuhan pribadi

\section{- Indikator Pelatihan Kerja}

Indikator-indikator pelatihan

menurut Mangkunegara (2011:46),

diantaranya:

1. Instruktur

2. Peserta

3. Materi

4. Metode

5. Tujuan

6. Sasaran

\section{KESIMPULAN}

Kegiatan Sosialisasi tentang pelatihan kerja di PDAM Tirtanadi Cabang Padang Bulan Medan dapat berjalan dengan lancar. Semua peserta terlihat antusias dan merasakan manfaatnya. Keberhasilan ini ditunjukkan antara lain:

1. Adanya kesesuaian materi dengan kebutuhan para guru untuk memahami tentang pelatihan kerja di lingkungan PDAM Tirtanadi Cabang Padang Bulan Medan.

2. Adanya respon yang positif dari peserta yang ditunjukkan dengan adanya diskusi yang cukup hangat dalam rangka implementasi pelatihan kerja di lingkungan PDAM Tirtanadi Cabang Padang Bulan Medan.

\section{REFERENSI}

Agustini, Fauzia, Manajemen Sumber Daya Manusia Lanjutan, Medan: Madenatera, 2011.

Bangun, Wilson, Manajemen Sumber Daya Manusia, Jakarta: Gelora Aksara Pratama, 2012.

Barthos Basir, Manajemen Sumber Daya Manusia, Jakarta: Bumi Aksara, 2012.

Hasibuan, Malayu, Manajemen Sumber Daya Manusia, Jakarta: Bumi Aksara, 2013.

Kasmir, Manajemen Sumber Daya Manusia (Teori Dan Praktik), Jakarta: Raja Grafindo Persada, 2016.

Maisyarah, Bani, Pengaruh Pelatihan Kerja dan Pengembangan Karir terhadap Kinerja Karyawan, Medan: Unimed, 2016.

Sinambela, Poltak Lijan, Manajemen Sumber Daya Manusia, Jakarta: Bumi Aksara, 2016.

Sondang P. Siagian, Manajemen Sumber Daya Manusia, Jakarta: Bumi Aksara, 2015.

Sugiono, Metode Penelitian Kuantitatif dan Kualitatif, Bandung: Alfabeta, 2014.

Suparyadi, Manajemen Sumber Daya Manusia, Yogyakarta: CV. Andi Offset, 2014.

Veithzal Rivai Zainal, Mansyur Ramly, Manajemen Sumber Daya Manusia Untuk Perusahaan, Jakarta: RajaGrafindo Persada, 2015.

Nasution, L., \& Ichsan, R. N. (2020). Sosialisasi Pemasaran Dalam Meningkatkan Loyalitas Mahasiswa Dan Alumni Fakultas Hukum Universitas Simalungun. PKM Maju UDA, 1(1), 31-36. Available at: 
http://jurnal.darmaagung.ac.id/index.php/ pkmmajuuda/article/view/702

Nasution, L., Anom, S., \& Karim, A. (2020). Pengaruh Program Sapta Pesona Dan Fasilitas Terhadap tingkat Kunjungan Objek Wisata T-Gardendi Kecamatan Deli Tua Kabupaten Deli Serdang. Jurnal Darma Agung, 28(2), 211-230.

Purba, N., Arfanti, Y., Nasution, L., \& Fitriani, R. (2020). Sosialisasi Kewirausahaan Dengan Budaya Malu Untuk Pencegahan Korupsi Di Desa Bandar Sono Kapupaten Batubara. AMALIAH:

JURNAL PENGABDIAN KEPADA MASYARAKAT, 4(1), 79-84.

Fikri, M. H., \& Nasution, L. (2018). Pengaruh Kepemimpinan Kepala Sekolah terhadap Efektivitas Sekolah di SMA Negeri 2 Medan. Jurnal Penelitian Pendidikan Sosial Humaniora, 3(2), 389-395.

Yusuf, Mohammad, and Reza Nurul Ichsan. "Analisis Efektifitas Penggunaan Cadangan Devisa, Utang Luar Negeri dan Ekspor Terhadap Stabilitas Nilai Tukar." JURNAL PENELITIAN PENDIDIKAN SOSIAL HUMANIORA 4.2 (2019): 544-561.

Ichsan, R. N. (2019). Kepemimpinan, Komunikasi Dan Efektivitas Kerja Pegawai Pemerintah Kota

Lhokseumawe. JUMANT, 11(1 ), 13-18.

Gaol, J.L., Ichsan, R.N., Hutabarat, L., The effect of working atmosphereand discipline towardemployee work productivityinpt. Duta

margalestarindomedan,

Journal of Advanced Research in Dynamical and Control Systems (2020), Pages:554564.

https://www.jardes.org/abstract .php?id=4882

Nasution, L., \& Rapono, M. (2018). Strategi Dalam Menghadapi Persaingan Perguruan Tinggi Di Propinsi Sumatera Utara Melalui Analisis SWOT (Studi Kasus UMN Al Washliyah Medan). JKBM (JURNAL KONSEP BISNIS DAN MANAJEMEN), 5(1), 9-24.

Nasution, L., \& Putra, M. G. (2018). Pengaruh Bauran Pemasaran dan Kualitas Pelayanan dalam Meningkatkan Loyalitas Mahasiswa Program Studi Manajemen Fakultas Ekonomi UMN Al Washliyah Medan. Jurnal Penelitian Pendidikan Sosial Humaniora, 2(2), 212-219.

Nasution, L., Fikri, M. H., \& Rapono, M. (2018, April). Penyuluhan Moderenisasi Pembelajaran Berbasis Teknologi Informasi Dan Komunikasi Di SDN 101808 Desa Candirejo Kecamatan Biru-Biru Kab. Deli Serdang. In Prosiding Seminar Nasional Hasil Pengabdian (Vol. 1, No. 1, pp. 165-175).

Nasution, L. Improving Quality Of Education Through Standards Educational And Aducational Personnel of SMA Unggulan $C T$

Foundation. EducanduM, 10(2 ) .

Nasution, L., Sagala, S., \& Daryanto, E. Kebijakan Kepala Sekolah Sebagai Supervisor Dalam Pengembangan Staf dan 
Kurikulum Di SMA Negeri 2 Medan. EducanduM, 11(2).

Nasution, L., Reza Nurul Ichsan, Mega Arisia Dewi, Buyung Perdana Surya, Efriyani Sumastuti, 2020. Emerging Supply and Demand as a Mix of Social, Economic, and Psychological Factors, Journal of critical reviews JCR. 2020; 7 (17) : 421-424.

http://www.jcreview.com/?mn $\underline{\mathrm{o}=19953}$

Reza Nurul Ichsan, E Surianta, L Nasution, 2020. Pengaruh Disiplin Kerja Terhadap Kinerja Pegawai Negeri Sipil (PNS) Dilingkungan Ajudan Jenderal Daerah Militer (AJENDAM) -I Bukit Barisan Medan, Jurnal Darma Agung 28(2), 187-210.

Ichsan, R. N., \& Nasution, L. (2019, September). Pengaruh Persepsi Kemudahan Penggunaan Dan Persepsi Daya Guna Terhadap Minat Nasabah Menggunakan Mandiri Online Pada PT. Bank Mandiri (Persero) KCP Gatot Subroto 2. In Prosiding Seminar Nasional Hasil Penelitian (Vol. 2, No. 2, pp. 1128-1136).

Nasution, L. and Choiriyah, S. and Rahmat, A. and Alam, H. and Salam. Utilization of data mining in the processing of average values of high school level national examination at the department of natural sciences in Indonesia. Journal of Advanced Research in Dynamical and Control Systems. 2020. volume 12. Number 6. Pages 2090-2096. https://www.jardcs.org/abstract $. \mathrm{php} ? \mathrm{id}=5244$
Yusuf, Mohammad, and Reza Nurul Ichsan. Analisis Efektifitas Penggunaan Cadangan Devisa, Utang Luar Negeri dan Ekspor Terhadap Stabilitas Nilai

Tukar. JURNAL PENELITIAN PENDIDIKAN SOSIAL HUMANIORA 4.2 (2019): 544-561.

Ichsan, R. N. (2019). Kepemimpinan, Komunikasi Dan Efektivitas Kerja Pegawai Pemerintah Kota Lhokseumawe. JUMANT, 11(1) , 13-18.

Gaol, J.L., Ichsan, R.N., Hutabarat, L., The effect of working atmosphereand discipline towardemployee work productivityinpt. Duta margalestarindomedan, Journal of Advanced Research in Dynamical and Control Systems (2020), Pages:554564.

https://www.jardcs.org/abstract .php?id=4882 